\title{
As inscrições da "diferença": corpo, subjetividade e experiência intersexual em espaços hospitalares*
}

Barbara Pires**

\begin{abstract}
Resumo
Este artigo reflete sobre os usos, as inscrições $e$ os significados de certos marcadores sociais da diferença no atendimento de três pacientes com variações intersexuais em um hospital público de alta complexidade no Rio de Janeiro. Para além dos gerenciamentos sociais e médicos desses pacientes, incorporo uma análise sobre a trama biomédica de gestação de determinadas "verdades" sobre corpos e vidas intersexuais. Na regulação diária desses casos, chaves analíticas são postas em jogo para demarcar as tramas de incitamento ou de silenciamento dos registros da "diferença" em espaços hospitalares, no que tange, por sua vez, à experiência da intersexualidade.
\end{abstract}

Palavras-chave: Intersexualidade, Marcadores Sociais da Diferença, Vulnerabilidade, Desigualdade, Consentimento.

* Recebido em 31 de agosto de 2016, aceito em 19 de setembro de 2018.

** Doutoranda no Programa de Pós-Graduação em Antropologia Social do Museu Nacional, Universidade Federal do Rio de Janeiro (UFRJ), Rio de Janeiro, RJ, Brasil. barbaragomespires@gmail.com 
Inscriptions of "Difference": Body, Subjectivity and Intersexual Experience in Hospital Spaces

\begin{abstract}
This article reflects on the uses, inscriptions, and meanings of certain social markers of difference in the care of three patients with intersex variations in a high complexity public hospital in Rio de Janeiro. Beyond the social and medical administration of these patients, I analyze the biomedical script for administrating certain "truths" about intersex bodies and lives. In the daily regulation of these cases, some analytical themes are brought into play to demarcate the incitement or silencing of the registers of "difference" in hospital spaces, notably in reference to the experience of intersexuality.
\end{abstract}

Keywords: Intersexuality, Social Markers of Difference, Vulnerability, Inequality, Consent. 


\section{Introdução}

A experiência da intersexualidade desde muito cedo se entrelaça em dois polos complementares: sua racionalização enquanto epistemologia, isto é, enquanto área de conhecimento sobre o corpo sexuado e suas variações, e sua vivência enquanto ontologia, ou seja, enquanto "modos de ser" que de algum modo desestabilizam os próprios alicerces cognitivos e socioculturais que fomentam essas vidas. Pretendo discutir sobre as experiências da intersexualidade na medida em que esses dois polos se entrelaçam $e$ se espraiam no mundo social. Quais seriam as marcas que circunscrevem as apreensões $e$ os sentidos da experiência intersexual? Mais exatamente, quais os marcadores sociais da diferença que são acionados para dar conta dessas experiências em encontros clínicos e em espaços hospitalares? Nesse sentido, o propósito geral deste artigo centra-se em buscar, a partir da dinâmica "médico-paciente" em espaços hospitalares, quais as assunções da "diferença" no que tange à experiência da intersexualidade. Dito de outra forma, pretendo discutir como a variedade de maneiras com que os "discursos específicos da diferença são constituídos, contestados, reproduzidos $e$ ressignificados" (Brah, 2006:374) nesse contexto modelará - assim como Bento (2006) discorreu sobre as/os transexuais - corpos, vidas e verdades específicas.

Nomeio esse processo, inspirado nas reflexões foucaultianas, de "veridicção da intersexualidade", no que não só o caráter administrativo do atendimento médico, mas também o caráter gestativo da ciência médica, se atualizam em suas técnicas e abordagens a fim de assegurar a produção de verdades acerca do corpo intersexual e do corpo sexuado em geral. Em outras palavras, o que chamo de processos, regimes ou modos de veridicção da intersexualidade está enraizados nas análises de Foucault (2008) sobre a biopolítica. ${ }^{1}$ Ao passo que, em uma

1 Foucault caracteriza o "dispositivo da sexualidade" nos séculos XVIII e XIX indicando que falar sobre o sexo constitui-se como uma tecnologia de poder. Em sua interpretação, a sexualidade ocupa um lugar privilegiado na gestão da vida 
conjuntura histórica, com muitas facetas, modifica-se a maneira com que a verdade é contada; formas específicas de inteligibilidade e subjetividade serão postas em jogo de acordo com essas discursividades - biomédicas e dos próprios sujeitos intersexuais. $^{2}$

Em suma, devido à preocupação social e científica em corrigir corpos sexuados não hegemônicos, a biomedicina (enquanto "saber-poder") leva ao limite estratégias de controle e de regulação do biopoder. Legitima-se cada vez mais diagnósticos urgentes e intervenções clínicas e cirúrgicas precoces em corpos de sujeitos intersexuais. A justificativa do sofrimento, que se repete desde o século XIX com o paradigma do caso de Herculine Barbin, invisibiliza as sistematizações generificadas e políticas (travestidas

não somente com a biopolítica, ou seja, nas formas de organizações políticas e regulações das populações, mas também na administração disciplinar dos corpos, seja pela medicalização da família através da vigilância e controle da sexualidade infantil, ou pela gênese religiosa do dispositivo da sexualidade com base na confissão-desvelamento, ou por fim, pela composição dos saberes psiquiátricos. Ainda nesta análise, o dispositivo da sexualidade, segundo Duarte (1999), coloca em jogo três aspectos fundamentais para se pensar a construção ideológica $e$ institucional desse momento histórico: a perfectibilidade (o aperfeiçoamento progressivo de si e da humanidade), a experiência (representando um modelo empirista de relação com o mundo) e o fisicalismo (investindo em uma distinção radical e cosmológica do corpo e do espírito) são aspectos que transformarão a forma com que se conhece o corpo sexuado humano. A exploração da corporalidade em seus limites - intensificando o uso do corpo para o trabalho disciplinar, para os prazeres, para a gestão da vida - explicaria a própria humanidade. Posto isso, os saberes e as práticas de regulação, gerenciamento $e$ veridicção do corpo sexuado instauram regimes de verdade sobre o que somos $e$ como devemos/podemos viver.

${ }^{2}$ A questão da veridicção em Foucault atravessa suas análises sobre poder $e$ conhecimento, além dos escritos sobre a sexualidade, e culmina na problemática da "parrhésia", isto é, a relação franca de sujeitos e subjetividades com a verdade. Nesse sentido, os regimes de verdade e as relações específicas entre sujeitos dentro desses processos (como a relação médico-paciente) "funcionam como uma prática de auto formação do sujeito", em que se pauta uma obrigação com a verdade de si (Wellausen, 1996:114). Esses jogos são conflituosos, com controvérsias e resistências, como iremos desenvolver a partir das experiências analisadas. 
com discursividades supostamente neutras, pois científicas) feitas nesses corpos que faltam ou excedem a normalidade.

Logo, o gerenciamento e a veridicção da intersexualidade ocorrem na medida em que o discurso científico visualiza os corpos intersexuais como não inteligíveis, isto é, quando o desenvolvimento sexual desses sujeitos é entendido como atípico para o padrão médico-científico do que seria correto para um desenvolvimento cromossômico, gonadal, hormonal e anatômico do sexo. Essa não conformidade corporal do que seria um processo lógico e natural de diferenciação e determinação do sexo se apresenta, portanto, como um problema. Nesse ponto, na prática médica, surge a necessidade do diagnóstico e da intervenção nos corpos intersexuais. E é papel do profissional de saúde ajustar tal ausência, excesso ou ambiguidade para modelos corporais que possam ser assimilados clínica e socialmente.

Contudo, essas veridicções e gerenciamentos teriam um caráter sociomédico, como bem concluiu Paula Sandrine Machado em diversas publicações (2005, 2008a, 2008b): os argumentos técnicos e científicos usados pelos profissionais de saúde não se limitariam às realidades biomédicas, eles também estariam constantemente articulados com aspectos socioculturais. Estes, por sua vez, ligam-se a noções múltiplas da diferença, nas quais a vulnerabilidade, a desigualdade, e também o consentimento aparecem como recursos possíveis para analisarmos como as experiências da intersexualidade se relacionam com os modelos $e$ as práticas biomédicas.

Este texto aborda, portanto, reflexões advindas de uma pesquisa etnográfica feita em três hospitais públicos de alta complexidade no Rio de Janeiro. Debruço-me aqui no estudo comparativo de três casos de pessoas com variações intersexuais, um recém-nascido e duas jovens de 18 anos, atendidos em um ambulatório de endocrinologia pediátrica em um dos hospitais pesquisados. Os três, além de compartilharem a experiência de nascerem com corpos designados como não usuais ao modelo hegemônico do dimorfismo sexual, também vivenciaram uma 
travessia biomédica a fim de terem seus corpos verificados $e$ conformados para os padrões inteligíveis da vida social.

Inscrições desiguais: "vulnerabilidade" entre o modelo $e$ a experiência

Todos os pacientes dos casos a serem descritos foram atendidos segundo investigações etiológicas e clínicas similares. O primeiro caso, de um bebê recém-nascido, o diagnóstico definido em prontuário era de Síndrome de Insensibilidade Parcial aos Andrógenos (SIPA). Em outras palavras, a SIPA é uma condição ligada ao cromossomo X que afeta pessoas com cariótipo 46, XY, nos quais há prejuízo total ou parcial do processo de virilização intrauterina devido à alteração funcional do receptor de andrógenos, isto é, dos hormônios masculinos (Melo et alii, 2005:88). A recepção, nesse caso, será parcial. Os outros dois casos descritos, de duas jovens de 18 anos, até o final de minha etnografia não tiveram etiologias fechadas por serem casos de pacientes vindas de outros estados, onde já tinham passado por atendimentos e procedimentos anteriores que não foram recuperados. Dito isso, a aproximação que realizo ocorre a partir das mesmas abordagens biomédicas, da similitude nos resultados clínicos e de uma mesma possibilidade diagnóstica que é debatida entre os casos devido, principalmente, a todos terem o mesmo sexo cromossômico.

Conheci os familiares $e$ o bebê do primeiro caso que descrevo logo no começo de minha etnografia, em maio de 2014. Michelle, a mãe, esperava na porta do departamento de endocrinologia pediátrica com sua prima, Frankie, que segurava Ana Luísa, de 2 meses de idade, no colo. ${ }^{3}$ Estavam aguardando a segunda consulta do bebê. As duas vieram, de metrô, de Acari ${ }^{4}$ até o hospital etnografado, localizado na Zona Norte do Rio de

\footnotetext{
3 Todos os nomes apresentados ao longo do artigo são fictícios.

${ }^{4}$ Os bairros, capitais e estados citados ao longo do capítulo foram trocados a fim de preservar a identidade $e$ a confidencialidade dos pacientes $e$ de seus familiares.
} 
Janeiro. A criança ainda estava sem registro civil e no prontuário do ambulatório era apenas identificada como "RN de Michelle". A falta de registro ocorria porque a mãe não tinha recebido a "declaração de nascido vivo" (DNV), documento que identifica o recém-nascido provisoriamente, do médico responsável pelo parto. A vinculação do número da DNV é obrigatória para que qualquer criança seja registrada civilmente em cartório. Sua emissão é de responsabilidade do profissional de saúde que acompanhou a gestação ou o parto do recém-nascido, de modo que se a variável "sexo" não for preenchida, como na hipótese de um caso de "genitália ambígua", impossibilita-se a produção do registro civil. ${ }^{5}$

Michelle, durante o acompanhamento de sua gestação, não teve definição do sexo de seu bebê. Nos ultrassons obstétricos que fazia, os especialistas discordavam entre a definição de menina $e$ menino. No último exame que realizou antes do parto, lhe foi dito que esperava uma menina. Entretanto, quando a criança nasceu os pediatras responsáveis anunciaram para a mãe que não podiam designar um sexo para a criança, e a encaminharam, junto com o bebê, para realizar o cariótipo no hospital em que fiz trabalho de campo. Levaram Ana Luísa, como a chamavam inicialmente, para o hospital com 3 semanas de vida. Perdidas à procura do ambulatório de genética, uma endocrinologista notou que o pedido encaminhado tinha como finalidade a "descoberta" da definição sexual do bebê. Ela então assume o caso ao conduzir a família para o ambulatório de endocrinologia pediátrica, usualmente responsável pela administração clínica dos casos de

\footnotetext{
${ }^{5}$ No dia $1^{\circ}$ de março de 2018, o Supremo Tribunal Federal decidiu, por unanimidade, a possibilidade de modificar o prenome e o sexo no registro civil sem necessidade de laudo psiquiátrico ou cirurgia de transgenitalização e sem autorização judicial, com a alteração podendo ser feita diretamente em cartório. Mas os impactos dessa decisão no que tange à intersexualidade ainda precisam ser avaliados, justamente porque o campo "sexo" ainda é pré-requisito para a produção do registro civil após o nascimento [http://www.stf.jus.br/portal/cms/verNoticiaDetalhe.asp?idConteudo=371085 acesso em 22 mar. 2018].
} 
intersexualidade. Nesse primeiro contato, além do exame de cariótipo já solicitado, também pediram uma bateria de exames hormonais e um ultrassom pélvico.

A necessidade de mediação técnica da biomedicina tem como objetivo principal evidenciar os sintomas da doença, a grande área de produção científica e de atuação biomédica. Mas também, e consequentemente, as mediações técnicas funcionam como forma de relacionar e legitimar as incongruências anatômicas cujos padrões normativos são fomentados por esse mesmo saber científico. Tal mapeamento ocorre por muitas vias, como imagens fotográficas reproduzindo versões médicas sobre o corpo sexuado e imagens de tecnologias diagnósticas, como o ultrassom obstétrico. Essa tecnologia específica pode ser entendida como um marco na assistência terapêutica feita ao longo da gravidez. A difusão e a estabilização desse tipo de ultrassom pode ser explicada pelo efeito material que tais imagens produzem, introduzindo precocemente os fetos no mundo da linguagem e do gênero. A tecnologia antecipa "a existência social futura do bebê" (Chazan, 2012:178) dentro de modelos generificados, pois, conforme Butler descreve, "o bebê se humaniza no momento em que a pergunta 'menino ou menina?' é respondida” (2008:162). Quando essa qualificação não acontece é preciso compreender as causas que impossibilitam a certeza imagética do sexo se consolidar.

Por isso é interessante notar o fato de a investigação diagnóstica ser feita através das mesmas mediações técnicas que falharam anteriormente. $\mathrm{O}$ ultrassom obstétrico foi incerto para definir o sexo do bebê de Michelle, mas o ultrassom pélvico não. Ele irá verificar mais profundamente a "verdade" do sexo ao traduzir a existência das gônadas, as quais auxiliarão na construção diagnóstica e posterior designação sexual da criança. Nessa racionalidade científica, as marcas corporais precisam cada vez mais serem examinadas em suas minúcias imagéticas $e$ moleculares: a ficção do corpo desvelado intrinsecamente. Não obstante, essas mediações não são objetivas nem neutras. É vital que um especialista decifre e interprete os significados inscritos na 
imagem. Contudo, essas decodificações também não serão revelações, mas formas específicas de visualizar o corpo sexuado através do "treinamento do olhar" biomédico (Machado, 2008a).

Dessa forma, dois meses depois da primeira consulta, mãe e prima retornam com Ana Luísa para receber a definição do sexo cromossômico. As duas são novas, a mãe com 24 anos e a prima com 19 anos. Elas moram na mesma rua, de modo que a prima sempre está por perto e se prontifica a cuidar do bebê. Ao longo dos meses de consultas, cada vez mais a prima assume para si a responsabilidade do cuidado da criança. Nessa segunda ida ao hospital, receberam a notícia de que Ana Luísa tinha, na verdade, o sexo cromossômico masculino, isto é, 46, XY. Em cada consulta realizava-se também um exame físico e a genitália do bebê era examinada. Do primeiro exame físico, constava no prontuário que ela media 2,1 centímetros, abaixo da média definida pelo "Consenso de Chicago", em que a medida infantil para um norteamericano do sexo masculino é de 3,4 centímetros com desvio padrão de 0,3 centímetros, ou seja, abrangendo um intervalo de normalidade entre 3,1 a 3,7 centímetros (Lee et alii, 2006:e490). No segundo exame físico, a genitália diminuíra ainda mais: a medida foi de 1,5 centímetros. As gônadas estavam palpáveis bilateralmente, com cerca de 1 milímetro, mas as saliências

6 Foi uma conferência proposta em 2005 pela Lawson Wilkins Pediatric Endocrine Society (PES) e pela European Society for Paediatric Endocrinology (ESPE), que reuniu cerca de cinquenta médicos de várias especialidades (e, apesar de pioneira nesse sentido, apenas duas participantes intersexo, as ativistas Cheryl Chase e Barbara Thomas) para discutirem e pensarem sobre os protocolos, manejos e gerenciamentos sociais, médicos e científicos que envolvem casos de intersexualidade. Como resultado da conferência foi publicado em 2006 o texto "Consensus Statement on Management of Intersex Disorders", que servia de guideline em níveis internacionais para os protocolos, manejos e gerenciamentos das condições intersexuais. Em 2016, outra reunião de especialistas formulou um novo documento sobre a gestão médica da intersexualidade, caracterizado como um "Global DSD Update Consortium". Mesmo com alterações significativas nos protocolos, manejos e direitos mais atuais, as implicações dessas mudanças ainda precisam ser avaliadas nos atendimentos hospitalares. 
labioescrotais apareciam pouco pragueadas e pigmentadas. $\mathrm{Na}$ escala médica, considera-se tal genitália com um Prader III. No prontuário, entre as opções "pênis", "clitóris" ou "falus", assinalaram a última opção na definição da genitália. Nas discussões clínicas do caso, referiam-se à criança como um DDS 46, XY com falus indeterminado/ambíguo. ${ }^{7}$ Logo, para os médicos, se tratava de um menino pouquíssimo virilizado. Na sala de estudos do ambulatório, as hipóteses formuladas eram de que o bebê não produzia hormônios androgênicos suficientes ou que esses hormônios não agiam corretamente devido a problemas nos receptores.

Quando constataram por meio de exames hormonais que os níveis de testosterona e dihidrotestosterona estavam nos padrões normais, perceberam que a falha estaria na recepção hormonal. O bebê tinha pouca sensibilidade para a absorção de hormônios androgênicos, por isso a baixa virilização. $O$ próximo pulo científico seria identificar a causa do problema de recepção; para isso precisariam realizar um sequenciamento genético, descobrindo a mutação que alterou a capacidade do receptor de se sensibilizar aos andrógenos. Tentaram pedir esse exame por intermédio de um pediatra do Grupo Interdisciplinar de Estudos da Determinação e Diferenciação do Sexo (GIEDDS), no Hospital de Clínicas/UNICAMP, mas não conseguiram. O procedimento não é simples, e possivelmente oneroso.

Portanto, a mediação da dúvida sexual para a certeza diagnóstica teria que ser feita por outro método. Agendaram uma reunião multidisciplinar para discussão do caso em conjunto com especialistas da urologia cirúrgica e psicologia. No dia da reunião multidisciplinar, três profissionais da endocrinologia pediátrica $e$ duas psicólogas que acompanhavam o ambulatório foram até o departamento de urologia para conversar com o chefe do

\footnotetext{
7 Proposta em 2006 pelo "Consenso de Chicago", o termo "Distúrbios do Desenvolvimento Sexual" (DDS) configura uma nova terminologia científica $e$ biomédica para tratar as condições intersexuais, afastando-se de termos anteriores como "intersexo" $e$ "hermafrodita".
} 
ambulatório dessa especialidade sobre o caso. Após a exposição dos dados clínicos, as psicólogas narraram as dificuldades familiares e sociais da família do bebê. A maior preocupação na reunião não era tanto com a falta de designação sexual da criança, mas o que, em seus discursos, era construído como um caso de um paciente com uma estrutura familiar precária. Como apontei, a mãe era muito jovem, com 24 anos, mas já tinha 6 crianças, contando uma que faleceu com 1 ano de idade e o bebê em questão. Aliada a essa visão de uma procriação prematura e em abundância, notava-se, em suas falas, registros que modulavam suas concepções do caso, associados à falta de escolaridade/capital cultural e à origem/classe social. Evidencio esses aspectos porque tais marcadores são fundamentais para compreendermos as dinâmicas biomédicas de hospitais públicos, em que essas crianças intersexuais e seus familiares estão inseridos. Nesse registro, a família de Ana Luísa, formada por pessoas negras, pobres, moradores de uma comunidade da Zona Norte do Rio de Janeiro, era percebida como disfuncional para garantir o melhor cuidado de uma criança, intersexual ou não.

Articulada aos registros citados acima, outra informação, obtida com a prima ${ }^{8}$ : a mãe era usuária de drogas, o que parecia comprometer em algum nível sua atenção, pois tinha muitos bloqueios para se expressar e entender o que os médicos comentavam ou perguntavam ${ }^{9}$, fato que aumentava a

8 Frankie relatou essa informação para os médicos após uma das consultas de Ana Luísa. A prima disse que a mãe usava cocaína e, às vezes, também maconha.

9 Em uma anamnese realizada pela psicóloga no ambulatório de endocrinologia pediátrica, a mãe citava que durante a gravidez, quando brigava com o parceiro, pai do bebê, ameaçava tomar remédios e abortar a criança. Ressalta o fato de que queria deixar seu parceiro "desesperado" para interromper a briga. Não se sabe até que ponto a fala é factual, pois ela lembrava da situação de maneira confusa, nem se existiria algum nível de abuso psicológico ou físico desse parceiro com Michelle para justificar tais ameaças. Relata manter essas advertências durante toda a gestação, mas que o aborto não era uma opção real. A prima escuta a história e diz que teria "batido nela" se concretizasse o aborto; 
indisposição dos médicos frente ao que percebiam como uma porosa estruturação familiar para o "bom crescimento psicossocial da criança". Como citei anteriormente, a prima Frankie acompanhava a mãe nas consultas e exercia o papel principal de cuidadora. Ela não deixava Michelle dar leite materno para Ana Luísa, com medo da influência das drogas, então alimentava a criança com leite em pó ou suco de laranja. Os médicos receitaram Nestogeno, um leite em pó mais enriquecido, mas elas argumentaram que não podiam pagar a diferença. Tinham enormes dificuldade financeiras, a ponto de somente uma acompanhar Ana Luísa nas consultas, pois só tinham dinheiro para uma única passagem de metrô.

O limite da construção médica de uma discursividade encapsulada na "vulnerabilidade social" da família e que também polarizava concepções específicas sobre "bem-estar" $e$ "sofrimento" foi estipulado quando a mãe apareceu com uma barriga saliente em uma das consultas, aparentemente grávida outra vez. Os comentários na sala de estudos eram muitos $e$ chegavam ao desânimo sobre a possibilidade de ligação das trompas femininas somente com 25 anos de idade. Nessa interpretação, para os profissionais de saúde, ligar as trompas seria um meio de ajudar Michelle a não engravidar descuidadamente $e$ aumentar ainda mais as condições de vulnerabilidade que a família se encontrava. Não questionavam a precariedade social do controle da mulher, negra, com seu próprio corpo, não demarcavam as desigualdades que ela vive para regular sua própria fertilidade; apontavam para o que achavam óbvio - ela precisava parar de ter filhos. Então, quando Michelle abortou involuntariamente (a hipótese é que sim, não tivemos como saber se drogas, a falta de pré-natal ou algum outro elemento contribuiu para o fim da gravidez), a sensação na sala de estudos do hospital era de atenuação do drama familiar.

enquanto isso, em meio às conversas da sala de consulta, segurava e embalava a criança no colo. 
Angela Davis e várias feministas negras norte-americanas escreveram fortemente durante todo o final do século $\mathrm{XX}$ sobre as dificuldades que a mulher negra e pobre vivia para garantir seus direitos reprodutivos. Face à essa violação, de serem continuamente invisibilizadas pela falta de políticas públicas que as atendessem dignamente (e que ainda hoje são marcadas por cortes raciais nas estratégias de controle populacional), várias mulheres passavam (e continuam passando) por procedimentos esterilizantes para terem um mínimo de controle sobre seu corpo $e$ sua reprodução (1981). A inscrição dessas pessoas em discursos de vulnerabilidade e precariedade social, de forma consciente ou não, pelos profissionais de saúde, faz com que a violação de direitos sexuais e reprodutivos fundamentais ainda seja uma norma ordinária para essas mulheres e suas crianças.

Nesse sentido, durante a reunião multidisciplinar decidiram duas direções de conduta. A primeira era relativa à definição sexual - precisavam se valer de qual procedimento para atestar o sexo mais verídico para o bebê? Segundo, em vista de todo o drama familiar exposto, tinham que decidir sobre quais seriam os gerenciamentos propriamente sociais do caso. Os cirurgiões estavam receosos em operar sem um diagnóstico fechado, por isso assinalaram que o primeiro passo seria comprovar a tese da Síndrome de Insensibilidade Parcial aos Andrógenos. Com tal etiologia comprovada, poderiam garantir a viabilidade cirúrgica para manutenção da funcionalidade reprodutiva e sexual da genitália masculina, assim como afinar seus padrões estéticos. Logo, os especialistas decidiram na aplicação de um teste: injetariam uma ampola de $2 \mathrm{ml}$ de testosterona durante três meses na criança. Se houvesse estímulo fálico, isto é, se a genitália virilizasse, a tese da SIPA seria comprovada e poderiam continuar com os procedimentos padrões para esse diagnóstico. Em relação à estrutura familiar, todos concordaram que era necessário encaminhar a família para o departamento do Serviço Social do hospital. Deveriam retornar na próxima semana, tanto para a aplicação da primeira dose de testosterona quanto para a consulta com a assistente social. 
A farmácia do serviço de atenção especializada para pacientes transexuais do hospital forneceu a caixa de Deposteron, contendo três ampolas de $2 \mathrm{ml}$, com $200 \mathrm{mg}$ de cipionato de testosterona cada, exatamente para os três meses do teste de virilização. A aplicação foi custosa para a médica responsável, o líquido da testosterona era oleoso, de tal forma que essa viscosidade dificultou a aplicação imediata. O bebê chorava muito. Parecia doer bastante. Lembrei das injeções de benzetacil (um antibiótico da família das penicilinas), também de líquido oleoso e aplicadas intramuscular, que magoavam a área por dias depois da aplicação, mesmo em um adulto. Em suma, não saberia precisar a prorrogação dessa dor, mas a coxa da criança certamente ficaria dolorida por algumas horas. Foi Frankie, a prima, quem levou o bebê para a primeira aplicação. Não tinham dinheiro para arcar com quatro passagens, então ela assumiu esse compromisso. Juntava dinheiro para essa locomoção com os serviços que arranjava e se sentia mais capaz para lidar com os manejos clínicos e com os cuidados da criança do que a mãe do bebê.

As aplicações se repetiram durante os dois meses seguintes. Se a injeção foi penosa, quais seriam os desenvolvimentos da interação da testosterona (suas composições e reações) com o corpo de um bebê de 3 meses de idade? Na bula do remédio, apontam-se os efeitos colaterais: possibilidade de ginecomastia ${ }^{10}$; alterações cutâneas, como alopecia, seborreia e acne; aumento da retenção de água, sódio, potássio, cálcio e fosfatos inorgânicos; náusea, dor de cabeça, ansiedade e depressão; inflamação e dor no local da administração intramuscular. Por fim, um aviso que alerta para o contrassenso desse manejo médico frente ao guideline científico, cuja prioridade aparente é a preservação da funcionalidade gonadal - o tratamento com altas doses de testosterona (e qual é a dose correta para um recém-nascido?)

\footnotetext{
${ }^{10}$ Crescimento atípico, logo, patológico, das glândulas mamárias e das mamas masculinas.
} 
pode reduzir ou interromper a espermatogênese, como também pode agir na redução dos testículos.

De modo que essas práticas biomédicas são realizadas precoce e continuamente, mas não há garantia do pleno desenvolvimento funcional, tanto em nível reprodutivo como sexual. Os estudos longitudinais são precários e pouco conclusivos. Conforme informa um pediatra britânico especificamente sobre o gerenciamento dos casos de insensibilidade androgênica:

Suplementos androgênicos podem ser úteis na puberdade em pacientes com resistência aos andrógenos, mas não são sempre necessários. Realiza-se cirurgias entre o segundo e o terceiro anos de vida para reparar hipospádias e trazer testículos não descidos para as bolsas escrotais. Ginecomastia ocorre ocasionalmente em adolescentes, $e$ pode ser preciso mamoplastias redutoras. (...) Entretanto, estudos com resultados desses procedimentos são poucos $e$ recortam um número pequeno de amostras. São necessários estudos com mais pacientes envolvidos que usem modelos padronizados e válidos para a mensuração da função sexual (Hughes et alii, 2012:1425-1426). ${ }^{11}$

Paralelamente, a família foi encaminhada para o Serviço Social. A conversa foi feita com Frankie, quem levou a criança outra vez para a consulta. Ela segurava o bebê no colo enquanto a assistente social perguntava sobre a estrutura familiar da casa de Michelle, sobre a parentela e qual a relação que tinham de suporte entre si, sobre o papel do pai da criança no cuidado dela (e no convívio com Michelle e seus outros filhos), enfim, perguntas que

\footnotetext{
${ }^{11}$ Tradução da autora. No original: "Androgen supplementation might be needed at puberty in patients with androgen resistance, but is not always necessary. Surgery is done during the second to third year of life to repair hypospadias and bring undescended testes into the scrotum. Gynaecomastia often occurs in adolescence, and requires reduction mammoplasty. (...) However, outcome studies are few and comprise small numbers. Studies with large sample sizes that use standardized and validated measures of sexual function are needed'.
} 
possibilitavam mapear certas condições de cuidado. Frankie sempre segurava Ana Luísa no colo, limpando a baba ou ajeitando a roupinha dela, e respondia aos questionamentos da assistente social. Em um determinado momento, mas com certa urgência, ela devolve todos os questionamentos com uma única pergunta: "vocês não vão tirar a criança da gente não, né?". Faz a pergunta com sofrimento, parecia algo sufocado, talvez desde as primeiras consultas e atendimentos. Frankie dizia ter esse receio há um tempo, mas somente com a assistente social efetivamente perguntando (mesmo com a intenção de mapear a trajetória de vulnerabilidade daquela família) suas percepções sobre o atendimento clínico, ela foi capaz de vocalizar suas ideias sobre as explicações médicas, e também suas vontades e seus medos. Quando a assistente social devolve que ela não poderia retirar Ana Luísa da família (uma resposta parcial, pois enquanto agente estatal se concluísse que tal situação familiar fosse prejudicial à criança seria obrigada profissionalmente a denunciar ao Juizado de Menores), Frankie fica visivelmente mais aliviada.

É relevante também notar suas observações sobre o manejo clínico dos profissionais de saúde. Quando questionada sobre o que entendia ser o problema da criança, Frankie disse não saber muito bem. Entendia a dificuldade de estabelecer um sexo definitivo para a criança, mas não entendia os motivos para a confusão. Disse não saber exatamente qual a condição carregada pelo bebê, somente que os médicos falavam "umas coisas aî" de difícil memorização e que aceitariam a intervenção dada pelos profissionais, pois só queriam o melhor para Ana Luísa.

Dito isso, embora a prática do ocultamento de informaçóes seja combatida na literatura médica atual, como forma de redefinir a prática médica viciada pós John Money, ainda é arriscado afirmar que a revelação sobre a condição da criança intersexual, os cuidados possíveis e a participação parental no processo decisório sejam completas. Como bem disse Frankie ao lembrar dos médicos discorrendo "umas coisas aí" sobre a dificuldade de determinação sexual do bebê. O "Consenso de Chicago" estabeleceu, desde 2006, que os manejos dos casos de 
intersexualidade sejam feitos com uma terminologia supostamente não estigmatizante, como DDS 46, XY, e cada vez mais descritiva, como Síndrome de Insensibilidade Parcial aos Andrógenos. Entretanto, essas classificações não têm um significado particular (ainda mais científico), cuja suposta neutralidade descritiva impulsionou a mudança no guideline, para pessoas sem conhecimento biomédico. ${ }^{12}$ Principalmente para familiares com recortes específicos de vulnerabilidade social. Frankie estava mais interessada em conseguir um trabalho para comprar roupas novas para o bebê do que entender as dinâmicas congênitas $e$ hormonais que levavam uma criança a se virilizar pouco e com isso ter seu sexo questionado, debatido e escrutinado até a determinação sociomédica legítima.

De acordo com María Elvira Díaz-Benítez (2012), a categoria "consentimento" aparece como uma chave fundamental para se pensar as práticas sexuais contemporâneas, e porque não também as práticas biomédicas, já que inserida em uma mesma racionalidade ocidental e moderna. Dentro dessa racionalidade, as crianças intersexuais seriam tuteladas pelo Estado porque gozam da categoria de sujeitos de direitos, mais especificamente de sujeitos de direitos especiais, visto que não podem consentir legalmente. Em seus termos:

O consentimento é o elemento central na definição da licitude de uma relação sexual (Vigarello, 1998) e está diretamente relacionado à categoria de sujeito contemporâneo, isto é, indivíduos com direitos inalienáveis em uma concepção individualista da sociedade (Vianna $e$ Lacerda, 2004). No debate jurídico contemporâneo, a noção

\footnotetext{
${ }^{12} \mathrm{E}$ conhecimento biomédico aprofundado, pois casos de intersexualidade são difíceis de serem diagnosticados e gerenciados, como se pode notar pelas descrições dessas histórias. Os próprios residentes ficavam chateados ao pegarem um caso de "DDS" para atendimento ambulatorial. Quando tinham que explicar o caso no grupo de estudos após a ronda de atendimentos, faziam-no com muitas dúvidas e desgaste. Um dos médicos sempre brincava ao dizer que essas dúvidas seriam "questões de prova", o que intensificava de certo modo essa espécie de cansaço entre os residentes com os casos de intersexualidade.
} 
de consentimento vincula-se à definição dos direitos de crianças e adolescentes a respeito do exercício de sua sexualidade. As crianças são vistas como sujeitos de direitos, e a violação de seus direitos é percebida como um crime contra a humanidade (Faleiros e Campos, 2000; Lowekron, 2012). Às crianças e adolescentes adjudica-se uma condição de vulnerabilidade, isto é, a ideia de que à diferença das pessoas adultas, eles não possuem maturidade nem psicológica nem física, questão que se aplica para a sua sexualidade. Tendo como principal marco a aprovação da Convenção sobre os Diretos da Criança pela Organização das Nações Unidas (ONU), em 1989, as crianças passaram a ser entendidas como sujeitos de direitos especiais, sujeitos que devem ser tutelados $e$ protegidos pela sociedade, a família e o Estado (DíazBenítez, 2012:257-258).

De todo modo, o grande problema não seria o paciente intersexual ou seus familiares consentirem com $\mathrm{o}$ encaminhamento protocolar biomédico, mesmo ao inserirem $e$ legitimarem esses sujeitos no que chamo de processo de veridicção da intersexualidade. Pois como seria não consentir? É necessário inserir o sujeito em regimes de verdade, e tais discursividades banham-se em orientações normalizadoras de certos marcadores sociais da diferença, especialmente o sexo/gênero e a sexualidade. A grande questão a ser evidenciada centra-se na crítica ao privilégio do discurso biomédico sobre esses corpos, condições e vidas, uma vez que esse mesmo discurso não tenciona suas capacidades particulares de produção de verdades corporais e afetivas.

Importante frisar, no entanto, que o privilégio de veridicção não é estritamente biomédico, por mais que a biomedicina detenha maior controle e administração no domínio das verdades desses corpos e vidas. $\mathrm{O}$ dispositivo biomédico explica, justifica e produz as realidades do corpo intersexual e sua constante necessidade de tratamento clínico e cirúrgico, mas essa necessidade se sobrepõe a outros domínios, por exemplo, ao mundo jurídico que circunscreve a criança enquanto sujeito de 
direitos especiais. A distribuição da "verdade" científica não se limita às construções biomédicas. Ela vai além, ao mobilizar pessoas e realidades em torno de marcadores sociais específicos. Quando os profissionais de saúde encaminham o bebê de Michelle para a assistente social, deslocam essa distribuição para outro lugar, ao tentarem lidar com a vulnerabilidade social da família por meio de procedimentos e encaminhamentos burocráticos e administrativos.

Adriana Vianna discorreu em diversos trabalhos $(2002,2005)$ sobre os deslocamentos dos princípios em torno da "menoridade" e da infância nas legislações brasileiras, especialmente nas últimas décadas, que reforçam contornos mais tutelares na administração dos sujeitos de direitos especiais. Por um lado, há um evidente aparato de controle e disciplina a partir de variados mecanismos de ordenamento social, mas, por outro, também há uma produção de redes e responsáveis por esses sujeitos. As estratégias que marcam essas transferências e obrigações espraiam-se da família para outras formas de administração capazes de intervir na vida do menor. De modo que instâncias e agentes podem (e devem) fiscalizar a vida dessas crianças e suas famílias, mas também realizam um trabalho classificatório e pedagógico sobre a forma correta desses sujeitos existirem.

No âmbito da governança e dos direitos globais, algumas normas internacionais surgem na tentativa de afinar ou de reorganizar a distribuição da "verdade" sobre os corpos e as vidas intersexuais ao impor responsabilidades à máquina administrativa estatal. Conforme aponta Paula Sandrine Machado (2008a) sobre os "Princípios de Yogyakarta", documento produzido em 2007 com objetivo de definir parâmetros sobre a aplicação da legislação internacional de direitos humanos em relação à orientação sexual $e$ identidade de gênero.

Nesse documento, elaborado por um grupo de especialistas em direitos humanos de 25 países, há um artigo que pode ser aplicado às cirurgias precoces voltadas às crianças intersex. O item b, do princípio 18, "Proteção contra abusos 
médicos", estabelece que os Estados deverão: "Tomar todas as medidas legislativas, administrativas e outras medidas necessárias para assegurar que nenhuma criança tenha seu corpo alterado de forma irreversível por procedimentos médicos, numa tentativa de impor uma identidade de gênero, sem o pleno e livre consentimento da criança que esteja baseado em informações confiáveis, de acordo com a idade e maturidade da criança e guiado pelo princípio de que em todas as ações relacionadas a crianças, tem primazia o melhor interesse da criança" (Princípios de Yogyakarta, 2007:25, apud Machado, 2008a:37).

Ainda em relação ao consentimento, a antropóloga $e$ bioeticista Katrina Karkazis (2013) advoga com outras pesquisadoras e especialistas do tema sobre a relutância médicocientífica em praticar de fato um "consentimento esclarecido". Nos termos das autoras, o conceito não se sustenta na visão do consentimento enquanto legitimação através de um formulário, mas na própria noção que os pacientes (e seus substitutos legais, como pais e parentes) têm do direito à autodeterminação, cuja validade se assenta na transparência e no (re)conhecimento dos possíveis tratamentos e suas escolhas. Para as especialistas,

Médicos têm um dever correspondente de repassar aos pacientes informações adequadas para garantir que eles possam realizar uma decisão informada sobre suas opções de tratamento, incluindo a decisão de não se submeter a tratamento nenhum. Uma confusão comum dentro e fora da medicina seria que consentimento esclarecido consiste meramente em assinar um formulário de consentimento (normalmente no dia marcado para a realização do procedimento) depois de uma discussão apressada sobre os riscos e encaminhamentos do tratamento (Jones, McCullough \& Richman, 2005). Contudo, consentimento verdadeiro $e$ significativo é um processo de comunicação contínua entre médicos e pacientes (Karkazis, Tamar-Mattis, \& Kon, 2010). Consentimento esclarecido requer que os médicos adotem medidas para garantir que seus pacientes tenham entendido 
as implicações imediatas e a longo prazo das intervenções médicas, como também apontar alternativas, dando tempo para que esses pacientes pesem as informações e sejam capazes de tomar decisões com o suporte dos profissionais de saúde sem coerção (Tamar-Mattis et alii, 2013:2).

Um contraponto interessante a essa visão é feito pelo pesquisador Iain Morland (2008), ele próprio intersexo, em que aponta uma crítica à posição ativista a favor de um consentimento e atendimento "centrado no paciente", pois tal percepção ainda se apoiaria em uma noção valorativa entre algo "exterior" $e$ "interior". A visão comum é de que a prática médica corretiva $e$ normalizadora se propõe a resolver os problemas do exterior, a genitália e a anatomia ambíguas, enquanto os movimentos sociais se prezam por uma interioridade pautada na experiência vivida $e$ no embodiement. Mas na verdade, para Morland, essa distinção seria mais problemática, pois os dois lados não seriam fixos e em algum momento também estariam no outro polo do binômio. Além do mais, em sua interpretação, tal distinção ainda fomentaria um regime hierárquico do bom e do mau manejo dos intersexuais, no qual o principal ponto seria simplesmente ter agência para decidir ou não sobre atendimentos e intervenções (uma concepção centrada no sujeito de direitos), e não questionar o próprio discurso da necessidade social e biomédica de tratar pessoas intersexuais.

De volta ao trecho citado, o comprometimento ético e clínico em esclarecer todos os passos da condição, das intervenções e das alternativas sociomédicas possíveis não me pareceu ser contemplado no caso de Ana Luísa, acredito que por toda a construção e a mediação da família como vulnerável socialmente. Os profissionais de saúde pareciam iluminados pelo modelo tradicional de autoridade médica, pois detinham um aval visivelmente incontestável de gerir o diagnóstico $e$ indicar os encaminhamentos possíveis para o bebê de Michelle. Mas essa aparente autoridade médica, como vimos, está sobreposta a outras necessidades de cunho burocrático e administrativo. Esses profissionais precisam definir um sexo para a criança intersexual, 
pois se não indicarem na "declaração de nascido vivo" qual o sexo do bebê, Ana Luísa não terá registro civil nem uma vida reconhecida aos olhos do Estado.

Talvez só tenha acompanhado uma dinâmica "médicopaciente" mais horizontal no caso narrado a seguir, de uma jovem adolescente cujas identidade de gênero feminina e orientação sexual heterossexual formadas ensinam muito sobre quais roteiros de sofrimento são reconhecidos pela distribuição das "verdades" científicas e administrativas. Então para além da constituição de um quadro de vulnerabilidade incorporada às vivências intersexuais, especialmente no caso de Ana Luísa, também há nas dinâmicas de gerenciamento e veridicção da intersexualidade a construção de uma "carreira moral" de sofrimento travestida em um discurso de "bem-estar" biomédico. Parece haver uma dificuldade, de fundo sociocultural, em aceitar certos roteiros de sofrimento $-e$ justificar esses apagamentos com intervenções clínicas e cirúrgicas. A própria concepção de "saúde" e de "bemestar" estariam ligadas a uma ideia de "qualidade de vida" que não é verbalizada em nenhum momento, mas que serve de modelo para as condutas médicas e científicas.

Segundo o médico e bioético Kenneth Rochel de Camargo Jr, categorias como sofrimento, vida, doença e saúde não são conceituadas ou definidas pelo saber biomédico, elas existem somente no "terreno da metafísica". Materializam-se na prática como categorias relacionais a fim de conformarem e consolidarem a racionalidade biomédica - e o seu fim prático: a clínica. Mais além, ele indica que a medicina parte do sofrimento, tanto historicamente quanto em cada consulta, para a busca da doença. No entanto, também aponta que tal processo é atravessado por outros aspectos não clínicos, mas de cunho subjetivo e cultural, que de certo modo contradizem os esperados distanciamento $e$ objetivação biomédica necessários para a análise das doenças. Em seus termos:

Uma contradição fundamental se destaca para o propósito desta argumentação: para o paciente, a experiência da 
doença (sofrimento) é um fato concreto, incapacitante de uma forma que transcende sua capacidade de autocuidado, tornando necessária a intervenção do especialista. Para o médico, o sofrimento é irrelevante, e o paciente, fonte de distorções. Sua relação se dá com a doença, e o paciente é um mero canal de acesso a ela. Um canal muito ruim, por sinal, já que introduz "ruídos" em níveis insuportáveis. (...) Assim, para o médico, a única realidade concreta é a da doença, expressão da lesão. O esquema referencial das doenças é, no entanto, mera classificação, artifício criado para enquadrar os fenômenos do processo saúde-doença. Ao esquecer isso, o médico passa a sobrevalorizar o artifício em detrimento do paciente, apagando seu sofrimento. É interessante notar que o médico, apesar de procurar sempre se colocar no polo objetivo desse confronto, não está imune, ele mesmo, às contradições da subjetividade, uma vez que seu raciocínio está sujeito ao crivo de sua experiência, instância de ressituação do conhecimento "objetivo" na sua práxis (1992:206, grifo no original).

Nesse sentido, as dinâmicas hospitalares do caso (e de muitos outros casos de intersexualidade) imprimem um atrito entre a experiência da práxis médica - do conhecimento "objetivo", restrito e controverso, porém, atravessado por orientações particulares das subjetividades de cada profissional de saúde - e a experiência do par "sofrimento/bem-estar" que o paciente e seus familiares vivenciam nesses contextos de cuidado $e$ de intervenção sociomédica. No fim, entre os produtos desse atrito, podemos identificar o problema dos direitos (sexuais e humanos) ao consentimento de fato esclarecido e, um passo antes, da própria necessidade dessas justificativas e procedimentos.

De volta ao caso, com o teste de testosterona produzindo efeito, a criança virilizou. De vestidos, saias, roupas rosas e roxas, no dia da segunda aplicação, a prima já levou a criança de vestido amarelo e contou que não a chamava mais de "Ana", agora era somente "bebê". No dia da terceira e última aplicação, tamanha era a virilização da genitália e dos traços da criança que a família se convenceu de que era um menino e modificou o nome para 
Wagner Luís. Com o mesmo nome do pai, a criança poderia, finalmente, receber alta. Logo, o bebê com 6 meses de idade, virilizado, ajustado ao código de roupas, cor e gramáticas masculinas, estava pronto para ser registrado. Depois da definição clínica no sexo masculino, realizaram o registro civil em nome de sua mãe, Michelle, e de seu pai, Wagner. Por fim, os profissionais de saúde encaminharam o bebê à urologia cirúrgica, com o objetivo de corrigir esteticamente a genitália da criança a fim de adequá-la aos padrões masculinos hegemônicos. Resta saber, conforme afirmou uma das psicólogas do ambulatório em comunicação pessoal, se Wagner Luís irá se apropriar da identidade sexual que lhe foi atribuída.

\section{Os limites do consentimento: a veridicção do gênero, da sexualidade $e$ das práticas sexuais}

Paralelo ao caso de Ana Luísa/Wagner Luís, acompanhei um pouco do atendimento de duas jovens intersexuais, ambas com 18 anos de idade. Suas experiências nos ajudam a aprofundar ainda mais os caminhos e sentidos com que a "diferença" é acionada, (re)significada e legitimada nesses encontros hospitalares, ou seja, nos ajudam a entender como consentir (e quais os limites desse consentimento) em situações de vulnerabilidade e desigualdade. Nesse sentido, suas histórias importam para a compreensão das dinâmicas biomédicas de atendimento aos casos de intersexualidade, além de iluminar as hierarquias $e$ os privilégios da construção $e$ da governança das "normalidades" e "verdades" sobre certos corpos e vidas.

De um lado, temos a história de Carla. Ela apareceu no ambulatório de endocrinologia pediátrica do mesmo hospital em que acompanhei o caso de Ana Luísa/Wagner Luís, com a tia. Nascida no interior do Maranhão, Carla tinha um namorado há alguns anos, por quem era muito apaixonada. Conta que ele tentava aprofundar a relação e ela não cedia, por medo. $\mathrm{O}$ namorado não entendia o motivo de tanto bloqueio. Pensou que selar seu compromisso e demonstrar seriedade com a relação 
fosse assegurar o comprometimento sexual dela, então a pediu em casamento. Ela, com 16 anos na época, se desesperou. Terminou com o namorado, cuja insistência se mantinha mesmo com o término e o afastamento de Carla. Sem saída, considerou e tentou se suicidar em vários momentos. Não sabia resolver o conflito, suas angústias não eram verbalizadas em casa. A mãe sempre em silêncio, como se escondesse um segredo. Um dia acumulou coragem e contou para a tia, que mora no Rio de Janeiro, sua história. Contou que até aquele momento não tinha menstruado e sequer possuía uma vagina. Estava muito angustiada, não sabia os motivos nem como resolver sua condição.

Um parêntese ao caso: o segredo e o silêncio são dimensões importantes nessas dinâmicas. Historicamente, no que tange os atendimentos biomédicos dos casos de intersexualidade, o profissional de saúde esteve sob uma norma que o obrigava a ocultar informações para os familiares ou jovens intersexuais. Posteriormente, esse profissional assume uma posição de encorajar o encobrimento, por parte dos familiares, de certos aspectos do diagnóstico e da condição da criança/jovem intersexual. Ainda hoje, o consentimento esclarecido $e \quad o$ revelamento integral das questões clínicas e sociais envolvendo a intersexualidade não são posicionamentos padrões nos atendimentos médicos, mesmo com os novos guidelines apoiando mudanças de manejo nesse sentido. Em vista disso, a dificuldade de incorporar tais mudanças nos atendimentos se deve ao fato de que outros marcadores sociais são acionados na construção e na administração dos casos e afetam a interpretação da "diferença" nessas relações, como a construção da vulnerabilidade social no caso de Ana Luísa/Wagner Luís a partir de fatores como escolaridade, classe e raça/cor. De modo que os pais dessas crianças e jovens intersexuais também partilham de códigos similares de conduta social, ou talvez incorporem essas posições biomédicas na medida em que são atendidos nesses espaços hospitalares, pois também passam a gerenciar segredos, vergonhas e estigmas (Sedgwick, 2007) que as experiências intersexuais de seus filhos $e$ filhas mobilizam socialmente. 
As inscrições da "diferença": corpo, subjetividade e experiência intersexual em espaços hospitalares

Portanto, pode-se dizer que o lugar do segredo nessas experiências imprime um mecanismo de constrangimento mais dramático do que a homossexualidade "no armário" analisada por Sedgwick. As regulações dos privilégios de visibilidade e das hegemonias de valores não são apenas para guardar um desejo, mas a invisibilidade total de um corpo sexuado - pelo menos até que ele seja normalizado.

A tia traz Carla do Maranhão até o Rio de Janeiro para morar com ela e juntas começam a investigar as possíveis explicações para o que acontecia com o corpo da sobrinha. Carla inicia seu atendimento médico em um hospital no centro da cidade, onde realiza o exame citogenético para definição do cariótipo, que confirma o sexo cromossômico de 46, XY. No prontuário descrevem a impressão diagnóstica, "DDS 46, XY", a mesma identificação do caso Ana Luísa/Wagner Luís. Não fica absolutamente claro o diagnóstico feito pela equipe médica anterior à chegada ao Rio de Janeiro e ao hospital etnografado, e, por todas as especificidades $e$ assimetrias articuladas no gerenciamento sociomédico dos casos de intersexualidade, é compreensível Carla não lembrar da etiologia específica de sua condição. Contudo, pelo histórico dos exames realizados, pelos relatos dela e da tia, e pela definição do sexo cromossômico, a condição também parece ser a Síndrome de Insensibilidade Parcial aos Andrógenos. ${ }^{13}$ Caso o diagnóstico de SIPA fosse completo, sua genitália não seria ambígua. Associados ao sexo

\footnotetext{
${ }^{13}$ Tanto Carla quanto Fabiane (a menina da outra história que iremos acompanhar), não tiveram definições exatas de suas etiologias. Os profissionais de saúde do hospital não tiveram acesso aos relatos e dados médicos de seus locais de origem. Portanto, aproximo as etiologias dos três casos narrados não como diagnósticos "originais" ou "oficiais", pois não há como validar nos prontuários antigos, mas como uma investigação diagnóstica que foi realizada segundo os mesmos critérios e resultados indicativos da SIPA: de genitália ambígua, definição do sexo cromossômico (46, XY), imagens de ultrassom e níveis hormonais. As variações moleculares para localização exata da condição de cada um só poderiam ser achadas com exames mais detalhados, como a tentativa da equipe de realizar um sequenciamento genético de Ana Luísa/Wagner Luís, o que não foi efetivado.
} 
cromossômico, no resultado da ressonância magnética pélvica, com contraste, os especialistas notaram duas formações ovaladas medindo cerca de 3,5 centímetros e localizadas nos canais inguinais: eram testículos não descidos. Observaram também estrutura peniana de dimensões reduzidas, e não perceberam evidências de útero e de ovários.

Nesse outro hospital, Carla realiza duas cirurgias, a primeira, em 2012, para a retirada das gônadas masculinas, e a segunda, em 2013, para a feminização de sua genitália e construção de uma "neovagina". $\mathrm{Na}$ anamnese feita durante a consulta na endocrinologia pediátrica no hospital etnografado, ela relata com abatimento e certa animosidade a maneira com que foi tratada no outro hospital. A lógica era de espetacularização do corpo ambíguo, com cenas de observação $e$ discussão das especificidades do caso na frente da paciente. A tia complementa o relato da sobrinha: "foi tão impactante [esse tipo de comportamento médico], acho que ficamos prontas para qualquer coisa". Tal crítica faz eco sobre o que foi dito acerca do "treinamento do olhar" e da reprodução desse habitus a partir da experiência da prática médica, centrada na observação clínica, $e$ das mediações científicas envolvidas (por exemplo, com as imagens fotográficas ou instrumentalizadas). De modo que a reprodução do saber biomédico ainda esbarra, regular ou ocasionalmente, dependendo dos contextos de análise, nesses limites de consentimento não esclarecido e de violações psicossociais e integridades corporais.

Desse modo, Carla chega ao hospital etnografado já operada, mas com resultados estéticos e funcionais insuficientes. Usava constantemente um dilatador vaginal para manter a pouca profundidade construída em sua vagina. O objeto é um cilindro plástico, ou de outro material, cujo objetivo é dilatar e estender o canal vaginal. Usa-se como recomendação médica posterior à realização de cirurgias de vaginoplastia a fim de não diminuir $e$ fechar o canal vaginal operado. Seu uso é bastante incômodo no dia-a-dia, pois dependendo do comprimento e diâmetro do dilatador, se assemelharia ao uso de um dildo/vibrador ou de um 
pênis. Logo, o esforço do seu uso contínuo torna-se uma marca material efetiva na ilustração da "carreira corporal" que tal caso expressa. Inspirada tanto em Goffman quanto em Foucault, a expressão abarca práticas como as descritas acima, de dilatação $e$ (re)construção de vaginas, caracterizando essas práticas como uma forma de suplício atualizado na construção cotidiana do selfe do gênero das pessoas intersexuais.

Além do dilatador vaginal foi prescrito o anticoncepcional Diane 35, que Carla tomava de maneira irregular. Por conseguinte, com a retirada das gônadas masculinas e o uso do medicamento com estrogênio e progesterona sintética, seu corpo feminizou ainda mais. No prontuário, os médicos indicaram M3 para o estágio de desenvolvimento dos seus seios, considerando um aumento da mama e da aréola, mas sem separação de seus contornos. ${ }^{14}$ Em relação à genitália, tratavam no laudo médico como "falus indeterminado/ambíguo", com 2,5 centímetros de comprimento e fusão parcial das saliências labioescrotais. Mesmo com a cirurgia feita no hospital do centro, os médicos concluíram que tais traços e medidas representavam um Prader III - sendo possivelmente um Prader IV pré-cirúrgico. Nas observações após às consultas, os profissionais notavam que os resultados não eram satisfatórios técnica e esteticamente para uma paciente cuja identidade de gênero era tão reiteradamente feminina.

Sua história de sofrimento $e$ angústia por não ter conseguido consumar sua relação com o ex-namorado, centrada na incompatibilidade de sua anatomia com a identificação de gênero feminina $e$ aliada ao vigoroso empenho em efetivar sua

\footnotetext{
${ }^{14} \mathrm{O}$ termo "M3" se insere em um método, proposto por um médico inglês chamado J. M. Tanner, para identificar os estágios de maturação sexual. As mamas seriam avaliadas quanto ao seu tamanho, forma e características $e$ definidas em uma tabela que vai do "M1", estágio infantil e pré-púbere, até o "M5", estágio adulto e pós-púbere. Essa identificação de maturação sexual é realizada em conjunto à análise dos pelos pubianos, cuja tabela de desenvolvimento sexual também é similar ao das mamas, indo de "P1" a "P5". O diagnóstico, portanto, é conjunto. No caso de Carla, o prontuário médico indica "M3P4".
} 
normalização corporal (representada pelo esforço do uso contínuo do dilatador vaginal, que só retirava para tomar banho $e$ ir ao banheiro, e tão rápido acabasse com sua higiene já o recolocava novamente), moldava a certeza do encaminhamento clínico e cirúrgico tão necessária aos manejos dos profissionais de saúde. A trajetória biográfica de Carla materializava as ficções e os ideais normalizados da feminilidade. Ao enumerar para a psicóloga que queria 1) não ter clitóris grande, 2) não usar mais o "molde" (dilatador) e 3) a construção de uma vagina esteticamente perfeita, Carla assumia, mesmo sem saber, os efeitos e as regulações dos gêneros inteligíveis biomedicamente. Como apontou Bento (2006) em relação às experiências transexuais, a narração da história de vida é uma interpretação que está relacionalmente ligada ao ambiente em que é evocada, portanto, ao contexto hospitalar (Bento, 2006:168). Logo, caracterizar a vagina que gostaria de ter, tomando para si esse modelo hegemônico de feminilidade, sem excessos ou ambiguidades, consolidava Carla nos roteiros de vida generificados normativamente, tal como sustentam também os saberes e as práticas biomédicas.

Os paralelos com experiências de transexualidade são importantes por vários motivos, dentre eles, pela discussão em torno da despatologização das identidades sexuais e pela inserção em procedimentos terapêuticos similares, tais como as cirurgias $e$ as hormonoterapias. Alguns pesquisadores fizeram esse debate crítico, dentre eles, Leite Jr. (2008) e Arán, Murta e Lionço (2009). Há, no entanto, diferenças entre o tratamento de pacientes intersexuais e transexuais, sendo as mais evidentes as pautas em torno da autodeterminação de suas identidades de gênero e da autorização via consentimento mais esclarecido de procedimentos médicos em seus corpos. Mas no fim, podemos constatar que tanto a intersexualidade quanto a transexualidade "levantam questões sobre que tipo de corpo alguém necessita ter a fim de reclamar pertencimento a algum gênero", ou além, "se a sensação de pertencimento a um gênero é fortalecida pela experiência de 
viver em um corpo que foi tocado pela tecnologia médica" (Morland, 2014:114). ${ }^{15}$

A conclusão da história de Carla, até o fim de minha etnografia, foi $\mathrm{O}$ aval da psicologia para encaminhamento cirúrgico. A vaginoplastia para aprofundamento do canal vaginal seria realizada com a garantia de uma "trajetória de normalização" (Machado, 2008a) congruente às áreas cinzentas dos guidelines, onde a regulação da sexualidade não aparece mais formalizada nos protocolos, mas ainda é um manejo essencial para o compromisso da funcionalidade heterossexual. Nesse caso, não havia imprecisões. A endocrinologia pediátrica manteve o uso de Diane 35 de forma continuada para refinar a feminização dos caracteres secundários. Em suma, ela era o exemplo da plasticidade de gênero moneyziana levada ao limite, pois mesmo com todos os "obstáculos" de seu sexo cromossômico, o sexo de criação feminino prevaleceu. O trabalho dos profissionais de saúde era efetivamente inseri-la, através das cirurgias "corretivas", na anatomia feminina coerente à sua identidade de gênero $e$, com isso, cessar o sofrimento e o estigma da incerteza sexual que Carla carregava.

De outro lado, temos a história de Fabiane, que assim como Carla, foi transferida de outro estado para atendimento no Rio de Janeiro. Natural de Rondônia, ou como gostava de apontar, de sua capital, Porto Velho, ela chega ao ambulatório de endocrinologia pediátrica do hospital com o pai, com um encaminhamento do Programa de Tratamento Fora do Domicílio (TFD), e anuncia em sua primeira consulta que "queria ter uma vagina normal".

Fabiane nasceu com "genitália ambígua", e foi registrada com sexo feminino, porém, desde os 3 meses de idade, cita que sua mãe notou um aumento de sua genitália. Aponta em seus

\footnotetext{
${ }^{15}$ Tradução da autora. No original: "In the context of trans studies, both intersex and transsexuality raise the question of what kind of body one needs to have in order to claim membership in a gender and whether a person's sense of belonging to a gender is colored by the experience of living in a body that has been touched by medical technology".
} 
relatos que somente aos 13 anos foi levada ao médico ${ }^{16}$, quando iniciou acompanhamento hospitalar para investigar sua condição. Nessa época, realizou o exame de cariótipo que identificou que o sexo cromossômico de Fabiane era 46, XY. Imagens de ultrassom também constataram a inexistência de útero e ovários. Mas nada foi feito. Posteriormente, durante a adolescência, Fabiane foi encaminhada para o Rio de Janeiro. Em 2013, foi submetida à uma biópsia gonadal em outro hospital da cidade. Quando os especialistas que a operaram encontraram testículos não desenvolvidos, por se tratar de uma jovem de 16 anos, logicamente decidiram pela remoção das gônadas. Em paralelo, também iniciaram uma hormonoterapia para feminização de seu corpo com doses progressivas de hormônios, a qual foi concluída por atingir a marca "M5P5" de maturação sexual, isto é, de desenvolvimento total mamário e de pelos pubianos. Nesse outro hospital, também foi submetida a uma clitoroplastia para diminuição de seu falus e confecção de pequenos lábios. Somente no segundo semestre de 2014, Fabiane é transferida para o hospital etnografado.

Encaminharam-na para a realização de uma vaginoplastia, isto é, assim como Carla, para a construção de um canal vaginal aprofundado. Mas diferentemente da primeira, os relatos de Fabiane durante a anamnese apresentaram ruídos para a equipe de especialistas. Sua história impossibilitava a construção direta de certezas e coerências clínicas a fim de assegurarem os

\footnotetext{
${ }^{16}$ Algumas hipóteses para esse fato: pelas informações da anamnese e dos prontuários disponíveis, não se sabe nada sobre as dinâmicas familiares que antecederam essa primeira ida (tardia do ponto de vista biomédico, pois já se encontrava, assim como Carla, na adolescência) ao hospital. Por que Fabiane e Carla não foram levadas quando recém-nascidas ou ainda crianças ao hospital? Parece haver uma maior gestão do silêncio e do segredo por parte dessas famílias. Talvez por ambas se encontrarem em recortes regionais onde se é mais difícil falar sobre e buscar atendimento para casos de intersexualidade. Ou talvez pela falta de estrutura biomédica dessas localidades em perceber e gerenciar tais condições, o que submete ainda mais essas famílias às situações de encobrimento de estigmas. A mesma discussão também foi feita por Anacely Costa (2014) no capítulo 3 de sua dissertação.
} 
procedimentos cirúrgicos. Somente sua autodeterminação ao dizer "eu queria ter uma vagina normal" não era suficiente para a expertise médica legitimar sua designação sexual e o encaminhamento cirúrgico demandado.

Identifico, a partir dos relatos médicos informais e das anotações nos prontuários, que tal mudança de conduta é localizada na falta de reiteração, por parte de Fabiane, de características e qualidades inseridas nos roteiros ideais femininos, e que transbordavam nos relatos de Carla. Primeiro, Fabiane identificava-se como homossexual. Sua orientação sexual já inviabilizava, na percepção biomédica, um procedimento cirúrgico realizado para o desenvolvimento funcional, tanto reprodutivo como sexual, de uma lógica heteronormativa. Nesse sentido, quando falou do seu desejo de aprofundar seu canal vaginal, um dos endocrinologistas pediátricos conta que precisou explicar para ela que um canal vaginal maior era necessário ao sexo heterossexual, com penetração de pênis, e não ao sexo homossexual. Operar Fabiane prontamente seria uma maneira de "desperdiçar a técnica" com alguém que não iria usar seu corpo para manter uma prática sexual coerente ao modelo estabelecido. Mas ainda que não soubessem sobre as minúcias da sexualidade lésbica, foi impactante perceber que não a encorajaram - assim como admiraram no discurso de Carla - o desenvolvimento de sua própria autonomia sexual. Na verdade, eles argumentaram a favor de um outro tipo de sexualidade e prática sexual.

Tais mudanças no manejo clínico de um mesmo diagnóstico enfatizam nuances biomédicas, nada sutis, das construções de humanidades e de corpos sexuados segundo um regime de verdade específico. As eficiências clínica e terapêutica, como dizia Georges Canguilhem, são inseparáveis. Em seus termos,

a clínica é inseparável da terapêutica e a terapêutica é uma técnica de instauração ou de restauração do normal, cujo fim escapou à jurisdição do saber objetivo, pois é a satisfação subjetiva de saber que uma norma está instaurada (Canguilhem, 2009:185). 
Logo, a homossexualidade produziria menos eficácia no processo de construção diagnóstica, pois seria uma orientação sexual assim como toda a concepção de intersexualidade pelo saber biomédico - não usual, ilógica e, no limiar, anormal.

Então por mais que Fabiane verbalize uma biografia de si em que se identifique como mulher, na percepção do discurso médico hegemônico algumas fissuras se formam na narrativa em relação à utilidade daquele procedimento cirúrgico visto sua orientação sexual, e também ao questionamento da validade de sua identidade de gênero posto que suas performances corporais eram mais masculinas. Quando Fabiane conta para os especialistas sua história de vida, as psicólogas apontam conflitos com a mãe que escapam sua própria narração. $\mathrm{Na}$ visão dos profissionais de saúde, mesmo afirmando sua identidade de gênero feminina, quando Fabiane lembra sobre uma época muito feliz em que morou com o pai e a madrasta, e podia vestir o que quisesse (uns "bermudões e chinelos de homem"), ela cria outra fissura ao roteiro esperado. Quando volta a morar com a mãe, durante a adolescência, comenta de brigas e de como ela tentava acabar com seu jeito aparentemente mais masculino; nas palavras da jovem, a mãe não permitia que Fabiane usasse nada que a fizesse parecer uma "sapata". Também não aceitava a orientação sexual da filha. Mas no decorrer da narração de sua história de vida, vislumbra-se uma mudança na atitude materna. Quando Fabiane finalmente veio ao Rio de Janeiro para a investigação médica, conta que a mãe deu de presente um "chinelo de homem" e ela mal acreditou. A mãe parecia incorporar, com conflitos e vagarosamente, as escolhas feitas por Fabiane. Contudo, a construção de sua trajetória de vida não era suficiente para os profissionais de saúde, já que essas reflexões de si ficcionalizam uma "verdade" do sexo aos olhos dos especialistas $e$, caso apresente qualquer ruído em relação à norma, ao tipo ideal esperado, a legitimidade da certeza diagnóstica e de intervenção não se produz. 
Mais uma vez, experiências de intersexualidade $e$ transexualidade se convergem, especialmente quando falamos do conflito de pessoas com "o gênero que foi imposto e com a impossibilidade de trânsito identitário" (Almeida; Murta, 2013). Justamente porque esses tratamentos são influenciados não só por concepções históricas sobre o sexo, o gênero e a sexualidade, mas também por contextos científicos, morais e sociais que se entrelaçam na conformação dessas identidades e seus cuidados. Mesmo assim, também se torna necessária a constatação de que a intersexualidade engloba muitas condições e variações biológicas (em termos cromossômicos, gonadais, hormonais e anatômicos do corpo sexuado), e não uma "ambivalência sexual" que se finda com a correção biomédica. De modo que tanto a compreensão de uma coerência entre anatomia e identidade, quanto a eficácia da intervenção corporal, se deslocam das práticas e dos discursos correntes voltados às pessoas transexuais - ainda que compartilhem processos terapêuticos similares.

Nesse sentido, as psicólogas que atenderam Fabiane tinham como objetivo a produção de um laudo médico atestando a veracidade do seu roteiro de vida. Isto é, com esse laudo as psicólogas autenticariam sua história, seu pertencimento ao sexo feminino e a possibilidade de intervenção cirúrgica. Sem o aval da psicologia, Fabiane não faria o procedimento. Nesse caso se estabelece uma inversão das especialidades com responsabilidade de gerenciamento $e$ veridicção da intersexualidade, com a psicologia no papel da especialidade relevante para a definição sexual. Mas não era somente a psicologia que tinha o poder de verificar a conformidade sexual da paciente. Um dia, Fabiane estava se consultando quando uma endocrinologista pediátrica comenta, no meio da sala de estudos, que a paciente era "muito masculina". Fabiane usava as mesmas roupas que Carla usou quando participei de sua primeira anamnese no ambulatório: jeans, camiseta e tênis all star. Mas, dessa vez, a aparência básica só evidenciava o ruído dos lugares desviantes de sua história, presumida como uma falta de cuidado não feminina. Quando o endocrinologista pediátrico responsável pelo caso, ao retornar da 
consulta, comenta achar Fabiane feminina, a outra médica rebate: "é porque ele não bate muito bem". Gostar de chinelos masculinos, bermudões, não ser vaidosa e ter orientação sexual homossexual eram indícios, para a maioria daqueles médicos, de que algo estava errado com o seu diagnóstico.

Então, no momento em que Fabiane confessa, em meio às explicações hegemônicas do profissional de saúde, não descartar a possibilidade de namorar homens também, uma faísca de esperança e desespero ilumina o ambulatório de endocrinologia pediátrica. Esperança porquê de tal forma se assegura a coerência diagnóstica, com a manutenção das funcionalidades reprodutiva $e$ sexual heteronormativas - exemplificada na cena da médica afirmando ser "muito importante abrir essa possibilidade" futura de sexo heterossexual para a paciente. Nesse registro, o procedimento cirúrgico seria aceito prontamente, como foi com Carla. Contudo, também há desespero, porque se existe um conflito com a identidade de gênero de Fabiane, como as psicólogas suspeitam, ela nunca conseguirá ser um homem funcional - pois teve seus testículos retirados $e$ cirurgias feminizantes realizadas.

A saída pensada pela equipe médica foi de, por enquanto, não autorizar o procedimento cirúrgico. Fabiane teria que ir, a contragosto, de volta para Rondônia e lá se submeter a um acompanhamento psiquiátrico para validar seu pertencimento na identidade de gênero feminina. De modo distinto às decisões médicas no caso de Ana Luísa/Wagner Luís e Carla, nas quais o primeiro, uma criança recém-nascida, não tinha autonomia de decisão/negociação sobre seus encaminhamentos biomédicos, e a segunda convergia seus relatos de vida com os roteiros ficcionais de gênero e de sofrimento legitimados pelos profissionais de saúde, Fabiane era um ponto fora da curva. Sua autodeterminação não tinha legitimidade, pois sua trajetória de vida produzia mais controvérsias que as esperadas para um caso de intersexualidade. Tornando-se praticamente uma paciente do processo transexualizador, ela só poderia ganhar o direito de modificar seu corpo com o laudo médico produzido após uma 
sequência de atendimentos. Durante esse tempo de prolongamento do sofrimento, pois não há adesão ao seu consentimento inicial, não podemos prever como os conflitos de certeza $e$ incerteza irão se destrinchar em sua subjetividade e em seu corpo.

Portanto, fica patente que o direito sexual de integridade corporal e de uso do próprio corpo (segundo garantias de autonomia e de autodeterminação dentro de concepções universais dos direitos humanos) são negadas quando aspectos particulares do sexo/gênero e da sexualidade desviam da norma. Quais os limites do consentimento nesses casos? Aparentemente não tão distantes. Na clínica, é a experiência subjetiva do profissional, mais até do que a expertise clínica, que contará como modulador de diagnóstico e intervenção dos casos. Se a discursividade biomédica percebe um determinado paciente com marcas produtoras de vulnerabilidade social ou se a trajetória de vida de outro paciente reverbere ruídos que fragmentem a coerência diagnóstica, o consentimento e consequentemente as intervenções clínica e cirúrgica serão assumidas pela equipe de profissionais de saúde para garantir a restituição da saúde/normalidade de tal pessoa.

Para além das molecularidades e das classificações cada vez mais descritivas do saber científico sobre a intersexualidade, é na marca "sexo-gênero-desejo" anunciada por Butler (2008) que regulações, incitações e silenciamentos de corpos acontecem. Essas marcas atravessam concepções normalizadas, então culturalmente instituídas, das realidades do que podem ser homens e mulheres. Nessas interpretações da biomedicina, pedir uma vagina mais profunda não se resume a uma escolha íntima de alguém, mas se relaciona a processos em que a própria intimidade é governada e (des)construída. A tentativa biomédica de veridicção do corpo humano sexuado está nessas narrativas, nas quais pessoas estranhas aos registros necessários e possíveis terminam com duas opções essencialistas: aceitarem os encaminhamentos biomédicos normalizantes ou continuarem com os suplícios da "incoerência" intersexual. Contudo, como notamos 
pelos relatos, a experiência da intersexualidade não se resume às duas opções, assim como esse processo de gerenciamento $e$ veridicção não está isento de fugas, manipulações ou reorganizações por parte das pessoas intersexuais.

Podemos dizer que produzir uma verdade sobre o sexo segundo repetições de ficções reguladoras é uma estratégia antiga do biopoder. Como está registrado nas memórias de Herculine Barbin, a estabilização de suas ambiguidades passava pela incorporação de modos de ser generificados segundo sua época, sendo a aparência e a confissão dois artifícios fundamentais dessa veridicção do sexo socialmente. Atualizadas contemporaneamente, como discutiu Bento (2006) acerca das manipulações ficcionais do corpo e da experiência transexual, a estética é uma variável significativa de negociação com a equipe médica, pois atua como um indicador de níveis de masculinidade e de feminilidade. Mais além, essas apresentações do gênero precisam ser reiteradas com roteiros coerentes de histórias de vida. A consulta psicológica/psiquiátrica se recicla como uma nova forma de confissão, na qual as jovens intersexuais têm que saber jogar, ou seja, necessitam expor suas histórias apontando a "longevidade dos conflitos" de suas identidades de gênero com suas anatomias - $e$ as roupas, os jeitos, as relações, as memórias $e$ as falas, todas contam para essa produção biomédica de certezas e coerências sobre o sexo.

\section{Considerações finais}

Vimos nessas experiências que a discursividade e a prática biomédicas conseguem fomentar e regular subjetividades e corpos a partir de acionamentos de marcadores sociais específicos, ao desvelarem que nem todo corpo sexuado corresponde às normas e aos roteiros compartilhados coletivamente que tornam possíveis conhecer e relacionar-se com o mundo. Desse modo, marcar quem pode ser "homem" e quem pode ser "mulher" ainda é, para muitas pessoas e em muitos lugares, uma necessidade compartilhada para a plena inserção na vida social. Mas decidir 
quais pessoas, quais trajetórias e quais roteiros merecem ter suas demandas corporais e afetivas aceitas torna-se uma tarefa à parte que merece atenção para compreendermos quem indica a "diferença", como ela é organizada e articulada, e como a inscrição de sujeitos, subjetividades e relações ocorre à revelia de disposições pautadas em direitos humanos, como a garantia a integridade corporal, a autodeterminação e o consentimento.

Importou neste artigo mostrar como as pessoas intersexuais vivem suas "diferenças" em espaços hospitalares, onde o saber e a prática biomédicos constituem o que é "verdadeiro" e o que não é. Esses pacientes intersexuais precisam dos profissionais de saúde para terem suas designações de sexo/gênero dadas ou para terem seus corpos adequados aos modelos hegemônicos do dimorfismo sexual, tanto funcional quanto esteticamente. E porque precisam, por existir uma necessidade de validar corpos a certos critérios de inteligibilidade, essas pessoas são inscritas em registros de diferença tratados como desiguais. Nesse sentido, no âmbito dos direitos humanos e sexuais, em que crianças e jovens intersexuais são reconhecidas como sujeitos de direitos especiais, visto que precisam de tutela para consentirem, o grande paradigma não seria somente a discussão do consentimento esclarecido em si mesmo, mas o privilégio do discurso e da prática biomédicos de inscreverem essas crianças $e$ jovens intersexuais em certas subjetividades e corpos, de regularem suas experiências, de determinarem "formas inumanas de humanização" (Cabral, 2006).

Se como diz Butler (2004:21) "o corpo implica mortalidade, vulnerabilidade, agência" e se "a pele e a carne nos expõem ao olhar dos outros, mas também ao toque e à violência", ${ }^{17}$ as inscrições desses pacientes, Wagner Luís, Carla e Fabiane, nesses registros da diferença mobilizam tanto marcadores sociais de sexo/gênero, sexualidade, desejo e prática sexual, classe, raça/cor, capital cultural, dentre outros, como também privilégios de

${ }^{17}$ Tradução da autora. No original: "The body implies mortality, vulnerability, agency: the skin and the flesh expose us to the gaze of others but also to touch and to violence". 
conhecimentos $e$ políticas locais/globais singulares que se legitimam ao se afastarem da experiência do "sofrimento" do paciente e do compartilhamento desses próprios registros da diferença que são encapsulados em noções hierarquizadas do que constitui a vulnerabilidade e a precariedade no outro. Dito de outro modo, na medida em que a vulnerabilidade é vista como uma condição não compartilhada, a agência dos sujeitos intersexuais torna-se circunscrita e restrita, isto é, desigual, pois invisibilizada por modelos hegemônicos e fragmentada dentro de um jogo de "consentimento esclarecido" nunca plenamente realizado.

Nesse sentido, a verticalidade dos atendimentos aguçados pela suposta objetividade biomédica é afinada pelas moralidades envolvidas nas constituições dessas diferenças. Por exemplo, ainda que uma das pacientes, Fabiane, deseje habitar na norma ${ }^{18}$ e ter seu corpo conformado hormonal e cirurgicamente aos modelos vigentes, ela só terá seu pleito aceito na medida em que passar pelo crivo biomédico dos roteiros morais e corporais possíveis de serem reconhecidos como verdadeiros e inteligíveis, em que a "verdade" estará pautada em concepções particulares do que é correto ou coerente à matriz de inteligibilidade cultural.

Nas histórias narradas percebemos um entrelaçamento entre preocupações tipicamente sociais, ou melhor, posicionadas como inquietações complementares às biomédicas, como o registro civil, os ajustes de roupas, as estruturas familiares, a identidade de gênero, as práticas sexuais, em associação com outras angústias propriamente biomédicas, relativas às dinâmicas hormonais, gonadais e cromossômicas do corpo sexuado. Mas vimos também que a inteligibilidade desses corpos não se encontra nos saberes $e$ protocolos científicos, por mais que eles sejam o norte do manejo clínico em espaços hospitalares. A inteligibilidade está nessas

\footnotetext{
${ }^{18}$ Cito Saba Mahmood para pontuar como a agência não precisa ser necessariamente pensada apenas em sua capacidade de resistir às normas, mas também importa ser entendida como "the multiple ways in which one inhabits norms" (Mahmood, 2005:15).
} 
relações sociais conflituosas, entre expectativas de bem-estar $e$ realidades de sofrimento, em que certos roteiros afetivos $e$ corporais serão aceitos, e terão seu encaminhamento biomédico reconhecido e fomentado, enquanto outros serão escrutinados, remanejados e silenciados.

\section{Referências bibliográficas}

ALMEIDA, Guilherme; MURTA, Daniela. Reflexões sobre a possibilidade de despatologização da transexualidade e a necessidade da assistência integral à saúde de transexuais no Brasil. Sexualidad, Salud y Sociedad: revista latinoamericana $\mathrm{n}^{\circ} 14$, Rio de Janeiro, IMS/UERJ, 2013, pp.380-407.

ÁRAN, Márcia; MURTA, Daniela; LIONÇO, Tatiana. Transexualidade e saúde pública no Brasil. Revista Ciência \& Saúde Coletiva, Vol. 4, n 14, 2009, pp.1141-1149.

BENTO, Berenice. A Reinvenção do Corpo: sexualidade e gênero na experiência transexual. Rio de Janeiro, Garamond, 2006.

BRAH, Avtar. Diferença, diversidade, diferenciação. cadernos pagu (26), Campinas-SP, Núcleo de Estudos de Gênero-Pagu/Unicamp, 2006, pp.329-376.

ButLER, Judith. Undoing Gender. New York, Routledge, 2004.

. Problemas de Gênero: feminismo e subversão da identidade. Rio de Janeiro, Civilização Brasileira, 2008.

CABRAL, Mauro. En estado de excepción: intersexualidad e intervenciones sociomédicas. In: CÁCERES, C. F.; CAREAGA, G.; Frasca, T.; PeCHENY, M. (ed.). Sexualidad, Estigma y Derechos Humanos. Desafíos para el acceso a la salud en América Latina. Lima, FASPA/UPCH, 2006, pp.69-90.

CAMARGO JR, Kenneth Rochel de. (Ir)racionalidade Médica: Os Paradoxos da Clínica. Physis 2(1), 1992, pp.203-228.

CANGUILHEM, George. O Normal e o Patológico. Rio de Janeiro, Editora Forense Universitária, 2009.

CHAZAN, Lilian K. "Para quem era cego, era tudo", ou o "divisor de águas": a chegada do ultrassom no Brasil pela voz de três pioneiros. 
In: FonseCA, C; RoHDEn, F; MACHADO, P. Ciências na Vida: Antropologia da Ciência em Perspectiva. São Paulo, Terceiro Nome, 2012, pp.153-183.

COSTA, Anacely. Fé cega, faca amolada: reflexões acerca da assistência médico-cirúrgica à intersexualidade na cidade do Rio de Janeiro. Dissertação (Mestrado em Saúde Coletiva), Universidade do Estado do Rio de Janeiro, 2014.

DAVIS, Angela. Women, Race and Class. New York, Vintage Books, 1981.

DíAz-BENíTEZ, María Elvira. Sexo com animais como prática extrema no pornô bizarro. cadernos pagu (38), Campinas-SP, Núcleo de Estudos de Gênero-Pagu/Unicamp, 2012, pp.241-279.

DUARTE, Luiz Fernando Dias. O Império dos Sentidos: sensibilidade, sensualidade e sexualidade na cultura ocidental moderna. In: HEILBORN, M. L. (org.) Sexualidade. O olhar das Ciências Sociais. Rio de Janeiro, Zahar, 1999, pp.21-30.

Foucault, Michel. O Nascimento da Biopolítica. São Paulo, Martins Fontes, 2008.

. Herculine Barbin: Being the Recently Discovered Memoirs of a Nineteenth-century French Hermaphrodite. New York, Vintage Books, 2010.

GOFFMAN, Erving. Estigma: notas sobre a manipulação da identidade deteriorada. Rio de Janeiro, Zahar, 1982.

. Manicômios, Prisões e Conventos. São Paulo, Perspectiva, 1996.

HugHES, levan A. et alii. Androgen Insensitivity Syndrome. Lancet 380, 2012, pp.1419-1428.

LEE, Peter A. et alii. Consensus Statement on Management of Intersex Disorders. Pediatrics 118(2), 2006, pp.e488-e500.

. Global Disorders of Sex Development Update since 2006: Perceptions, Approach and Care. Horm Res Paediatr 85 (3), 2016, pp.158-180.

LEITE JR., Jorge. "Nossos corpos também mudam": sexo, gênero e a invenção das categorias "travesti" $e$ "transexual" no discurso científico. Tese (Doutorado em Ciências Sociais), PUC-SP, 2008. 
MACHADO, Paula Sandrine. O Sexo dos Anjos: um olhar sobre a anatomia e a produção do sexo (como se fosse) natural. cadernos pagu (24), Campinas-SP, Núcleo de Estudos de GêneroPagu/Unicamp, 2005, pp.249-281.

- O Sexo dos Anjos: representações e práticas em torno do gerenciamento sociomédico e cotidiano da intersexualidade. Tese (Doutorado em Antropologia Social,) Universidade Federal do Rio Grande do Sul, 2008a.

. Intersexualidade e o "Consenso de Chicago": as vicissitudes da nomenclatura e suas implicações regulatórias. Rev. bras. Ci. Soc. 23(68), 2008b, pp.109-124.

MAHMOOD, Saba. Politics of Piety. The Islamic Revival and the Feminist Subject. Princeton, Princeton University Press, 2005.

MELO, Karla F.S. et alii. Síndrome de Insensibilidade aos Andrógenos: análise clínica, hormonal e molecular de 33 casos. Arq Bras Endocrinol Metab 49(1), 2005, pp.87-97.

MORLAND, Iain. Intimate Violations: Intersex and the Ethics of Bodily Integrity. Feminism \& Psychology 18(3), 2008, pp.425-430.

. Intersex. TSQ: Transgender Studies Quarterly, vol. 1, Mai., 2014, pp.111-115.

PIRES, Barbara. Distinçóes do Desenvolvimento Sexual: percursos científicos e atravessamentos políticos em casos de intersexualidade. Dissertação (Mestrado em Antropologia Social), Museu Nacional, Universidade Federal do Rio de Janeiro, 2015.

SEDGWICK, Eve Kosofsky. A Epistemologia do Armário. cadernos pagu (28), Campinas-SP, Núcleo de Estudos de Gênero-Pagu/Unicamp, 2007, pp.19-54.

TAMAR-MATTIS, Anne et alii. Emotionally and cognitively informed consent for clinical care for differences of sex development. Psychology \& Sexuality 5(1), 2013, pp.1-12.

VIANNA, Adriana. Limites da menoridade: tutela, família e autoridade em julgamento. Tese (Doutorado em Antropologia Social), Museu Nacional, Universidade Federal do Rio de Janeiro, 2002. 
. Direitos, moralidades e desigualdades: considerações a partir de processos de guarda de crianças. In: LiMA, Roberto Kant (org.). Antropologia e Direitos Humanos 03 - Prêmio ABA / Fundação Ford. Niterói, EdUFF, 2005, pp.13-68.

Wellausen, Saly. Michel Foucault: parrhésia e cinismo. Tempo Social 8(1), São Paulo, 1996, pp.113-125. 